\title{
Non-powered dust removal device attached underneath a train cabin in a subway tunnel
}

\author{
G. N. Bae ${ }^{1,2}$, J. B. Kim ${ }^{1,2}$, S. H. Woo ${ }^{1,3}$, S. J. Yook ${ }^{3}$, \\ H. K. Park ${ }^{4} \&$ H. H. Yoon \\ ${ }^{1}$ Center for Environment, Health and Welfare Research, \\ Korea Institute of Science and Technology, Republic of Korea \\ ${ }^{2}$ Green School, Korea University, Republic of Korea \\ ${ }^{3}$ Department of Mechanical Engineering, \\ Hanyang University, Republic of Korea \\ ${ }^{4}$ Annex Research Institute, DK Industrial Co., Ltd., Republic of Korea \\ ${ }^{5}$ Technology Research Center, \\ Seoul Metropolitan Rapid Transit Corporation, Republic of Korea
}

\begin{abstract}
In megacities, a subway system is a powerful means of public transportation, carrying people every day. Due to wear of train wheels and rails, dust is heavily generated and dispersed in tunnels and platforms. For the improvement of air quality in subway tunnels, a non-powered dust removal device consisting of two inertial separators, such as a louver and baffle, was designed. This device can be installed underneath the train cabin to remove dust as soon as it is generated. Prior to design of the device, distributions of airflow velocity and dust concentration underneath the train cabin during the operation of the subway train were investigated. Average airflow velocity was found to be approximately $26 \%$ of train speed during the cruising period. The fractional dust removal efficiency and pressure drop of the lab-scale dust removal device were tested in a wind tunnel. Removal efficiency of particles smaller than $10 \mu \mathrm{m}$ is approximately $60 \%$ at $4 \mathrm{~m} / \mathrm{s}$.

Keywords: subway tunnel, dust removal device, air quality, dust, airflow velocity.
\end{abstract}




\section{Introduction}

In megacities, a subway system is a powerful means of public transportation carrying many people every day. Subway trains are operated in isolated underground tunnels. Due to wear of train wheels and rails, dust is heavily generated and dispersed in tunnels and platforms [1]. Recently, in Korea, platform screen doors have been installed at most stations for passenger safety. Therefore, air in tunnels has become more severely polluted with dust [2]. The deteriorated air may penetrate the train cabin, posing a threat to the health of passengers who use the subway daily. A dust removal method using magnetic dust collectors underneath operating subway trains was suggested [3]. Recently, airflow velocity distribution and particle trajectories underneath the subway train were analyzed numerically [4]. To improve air quality in subway tunnels, effective dust removal devices should be developed urgently.

In this work, a non-powered dust removal device was designed to remove the dust generated from wheels or rails by operation of subway trains. Distributions of airflow velocity and dust concentration under the operating subway train were investigated. Performance of the dust removal device was also tested in a wind tunnel. This device will be installed underneath the train cabin to remove dust as soon as it is generated.

\section{Experimental}

Prior to design of the non-powered dust removal device, distributions of airflow velocity and dust concentration underneath a train cabin were investigated during the operation of a subway train. Airflow velocity was measured using a threedimensional ultrasonic anemometer (3-axis wind sensor, model 81000, R.M. Young Company, USA) and dust concentration was monitored using an aerosol monitor (DustTrak DRX Aerosol Monitor, model 8533, TSI, USA). These instruments were installed underneath the operating subway train using a frame (as shown in fig. 1). The measurements were made on line 5 of the Seoul Metropolitan Rapid Transit System on February 10th and 26th, 2015.

A non-powered dust removal device consisting of two inertial separators such as louvers and baffles was designed (as shown in fig. 2(a)). The lab-scale dust removal device was fabricated to investigate fractional dust removal efficiency and pressure drop with airflow velocity in a wind tunnel (as shown in fig. 2(b)). A schematic of the wind tunnel facility is shown in fig. 3 . The airflow velocity in the test section was controlled in the range of 1 to $6 \mathrm{~m} / \mathrm{s}$. Arizona dust was injected upstream of the test device using a dust generator (Solid Aerosol Generator, model SAG 410, Topas, Germany). The fractional dust removal efficiency was determined by simultaneous measurements using two optical particle counters (Portable Aerosol Spectrometer, model 1.109, Grimm, Germany) both upstream and downstream of the test device. The pressure drop across the test device was also measured using a differential pressure gauge. 


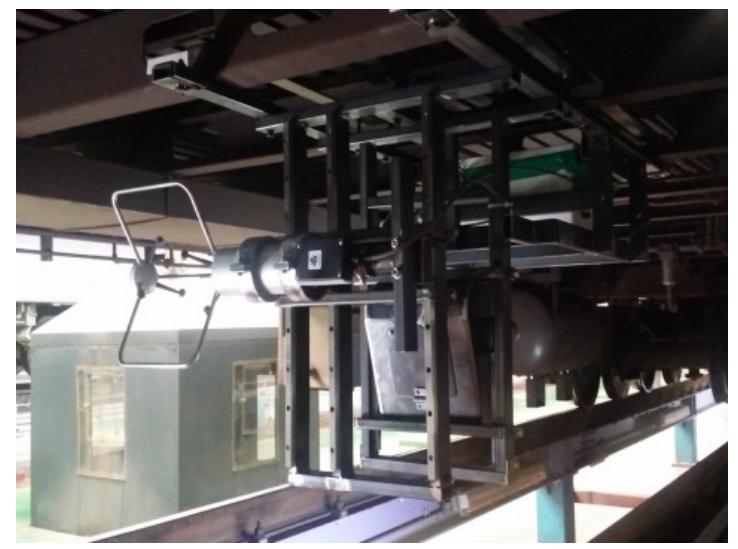

Figure 1: Photograph of airflow velocity and dust measuring instruments attached underneath the train cabin.

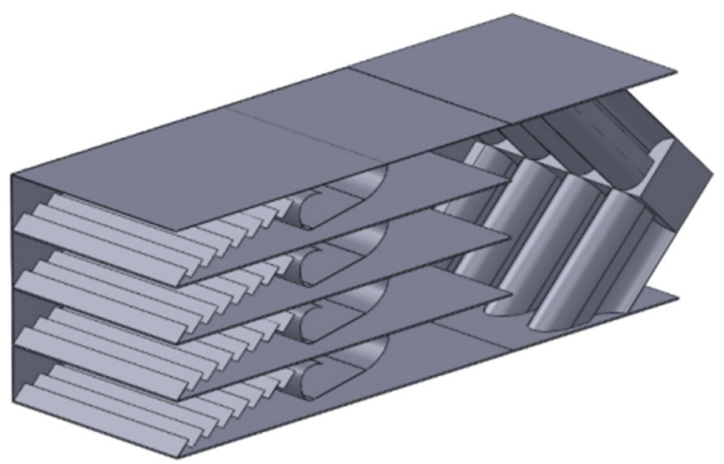

(a) Conceptual view

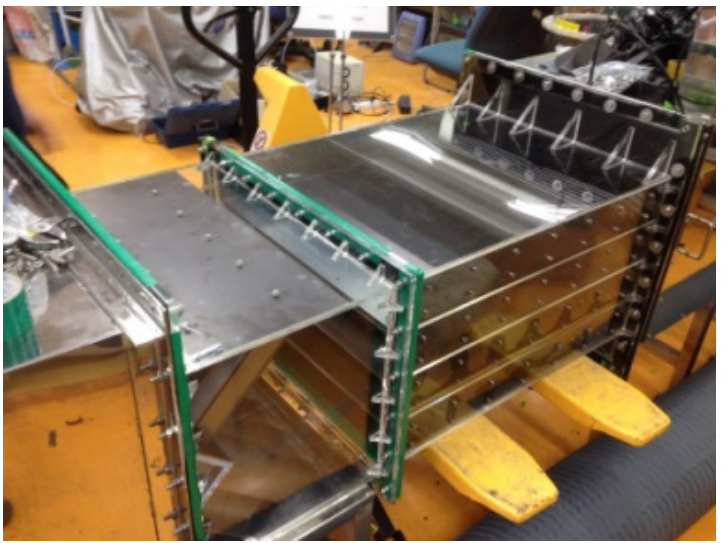

(b) Prototype for wind tunnel test

Figure 2: A non-powered dust removal device tested in this work. 


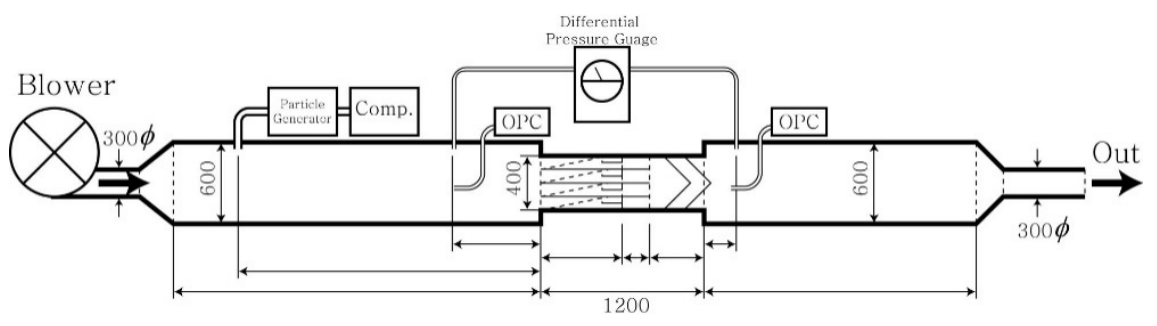

Figure 3: Schematic of the wind tunnel facility used in this study.

\section{Results and discussion}

A subway train operates in stop and go mode between stations. The operation pattern of the train can be classified into four operation periods by train speed: acceleration, cruising, deceleration, and stop. A subway train route also consists of a mixture of straight and curved sections due to geographical and social reasons. Therefore, the sections between stations were classified into three groups in this study: straight, curved, and mixed sections. Eleven straight sections and eleven curved sections were selected among forty-four sections of the target subway line.

The distributions of train speed, airflow velocity and $\mathrm{PM}_{10}$ concentration are compared in figs $4(\mathrm{a})$ and $4(\mathrm{~b})$. Here, $\mathrm{PM}_{10}$ is the mass concentration of particulate matter smaller than or equal to $10 \mu \mathrm{m}$ in aerodynamic diameter. Note that $\mathrm{PM}_{10}$ concentration was also determined using an optical measurement technique. V1 indicates the train speed and V2 denotes the wind velocity underneath the train in the driving direction. The averages of train speed and airflow velocity for the eleven straight sections were 18.8 and $4.9 \mathrm{~m} / \mathrm{s}$, respectively. The averages of train speed and airflow velocity for the eleven curved sections were 15.4 and $4.1 \mathrm{~m} / \mathrm{s}$, respectively. These averages represented approximately $80 \%$ of the train speed and velocity of the straight sections. The average airflow velocities underneath the train cabin were approximately $26 \%$ of the train speed during the cruising period. Average $\mathrm{PM}_{10}$ concentrations underneath the train cabin ranged from 247 to $467 \mu \mathrm{g} / \mathrm{m}^{3}$. Note that airflow velocity and $\mathrm{PM}_{10}$ concentration under the train cabin significantly depend on the measuring location. Therefore, more detailed measurements of spatial distribution of airflow velocity and $\mathrm{PM}_{10}$ concentration are required.

Pressure drop and dust removal efficiency are two important performance factors of dust removal. The pressure drops across the entire device and the louver part were separately evaluated (as shown in fig. 5). Here, face velocity is determined by the air flow rate divided by the cross-sectional area of the device. The pressure drop curves show a parabolic increase with face velocity of the test device.

The dust removal efficiency was evaluated by particle size $\left(d_{p}\right)$. These fractional dust removal efficiencies for louver part and the entire device are shown in figs 6(a) and 6(b), respectively. Because the device was designed to 
remove dust using its inertial impact, dust removal efficiency increases with both particle diameter and face velocity. The cut-off diameters showing $50 \%$ removal efficiency are $3.8,3.1,2.65$, and $2.5 \mu \mathrm{m}$ for $1,2,3$, and $4 \mathrm{~m} / \mathrm{s}$, respectively. Removal efficiencies of $\mathrm{PM}_{10}$ are $46,52,57$, and $61 \%$ for $1,2,3$, and $4 \mathrm{~m} / \mathrm{s}$, respectively.

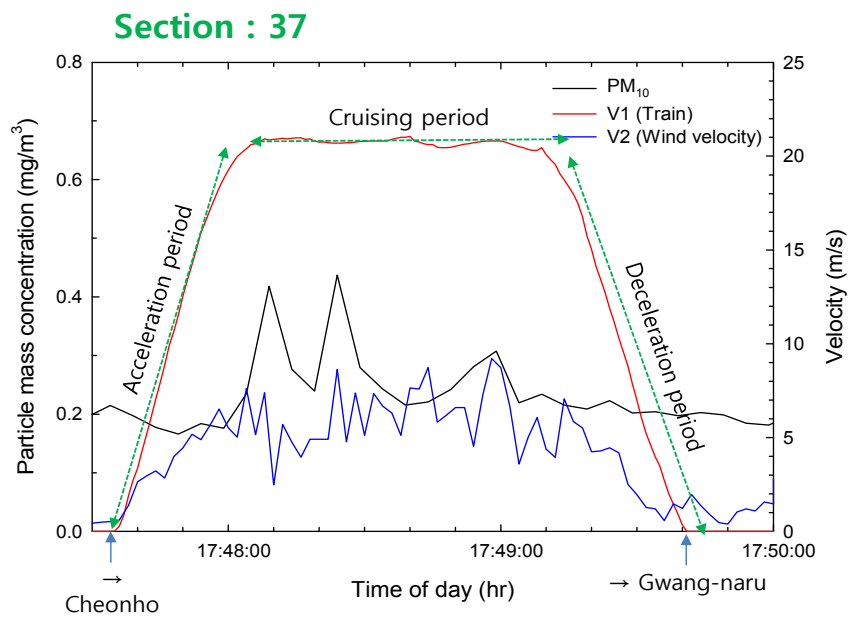

(a) Straight section

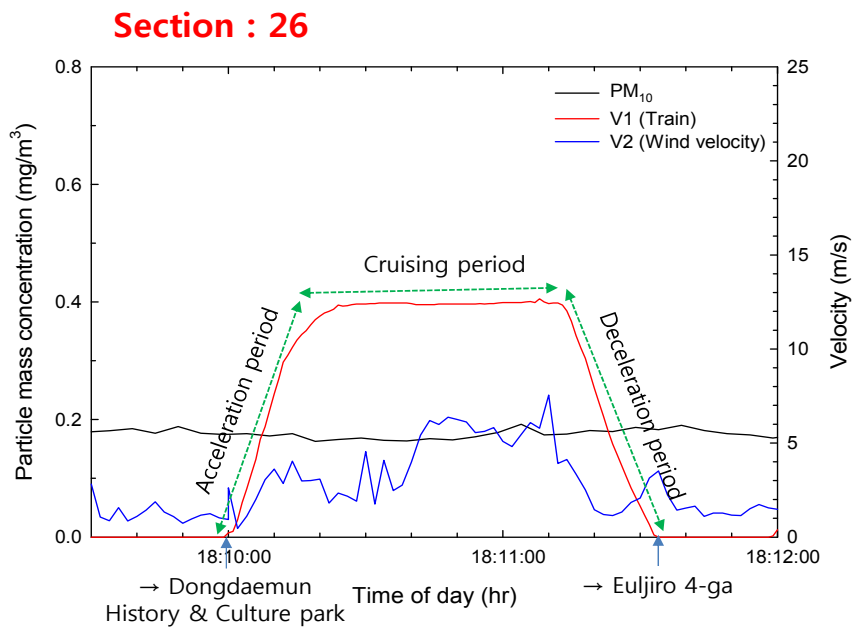

(b) Curved section

Figure 4: Variation of train speed and airflow velocity and $\mathrm{PM}_{10}$ concentration underneath the train cabin in a subway tunnel. 
330 Sustainable Development, Vol. 1

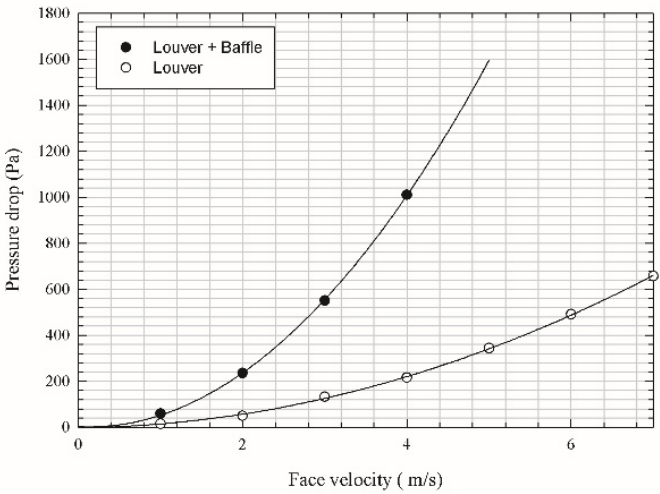

Figure 5: Variation of pressure drop with airflow velocity.

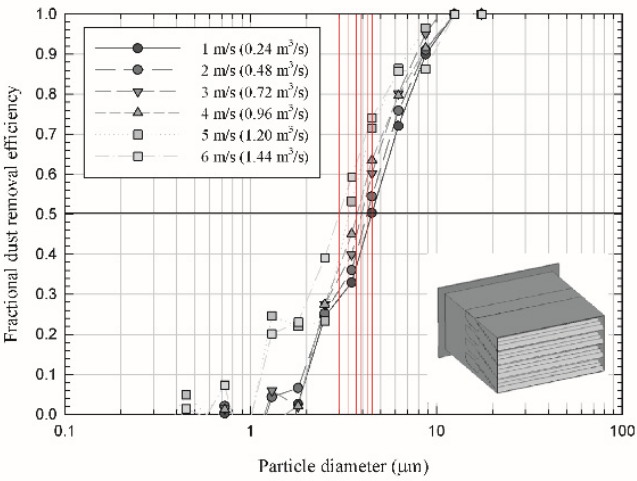

(a) Louver part

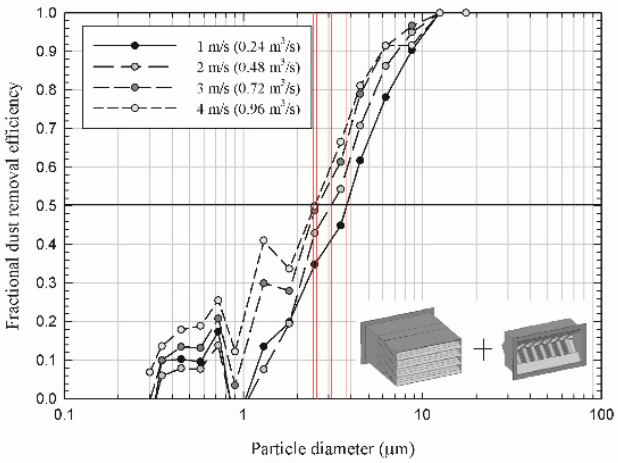

(b) Full device

Figure 6: Variation of fractional dust removal efficiency with face velocity. 


\section{Conclusions}

In this work, a non-powered dust removal device was designed for improvement of air quality in subway tunnels. Because this device uses train-induced wind, the airflow velocity and $\mathrm{PM}_{10}$ dust concentration were measured to obtain design information. The relation between airflow velocity and train speed was analyzed from the measured data. It was found that the average airflow velocities underneath the train cabin were approximately $26 \%$ of the train speed during the cruising period. From the wind tunnel test, a parabolic increase curve of pressure drop was obtained for the dust removal device. The cut-off diameter of the device was determined to be $3.1 \mu \mathrm{m}$ at $2 \mathrm{~m} / \mathrm{s}$ and $\mathrm{PM}_{10}$ removal efficiency was $52 \%$ at $2 \mathrm{~m} / \mathrm{s}$ from the fractional dust removal efficiency curves.

\section{Acknowledgement}

This work was supported by research grants on the Railway Technology Research Project by the Ministry of Land, Infrastructure and Transport, Republic of Korea (14RTRP-B081249-01).

\section{References}

[1] Park, J.H., Woo, H.Y. \& Park, J.C., Major factors affecting the aerosol particulate concentration in the underground stations, Indoor and Built Environment, 23(5), pp. 629-639, 2014.

[2] Kim, J.B., Kim, S., Lee, G.J., Bae, G.N., Cho, Y., Park, D., Lee, D.H. \& Kwon, S.B., Status of PM in Seoul metropolitan subway cabins and effectiveness of subway cabin air purifier (SCAP). Clean Technologies and Environmental Policy, 16(6), pp. 1193-1200, 2014.

[3] Park, J.H. \& Park, D., Method of removing Fe particulate matters from subway environments, International Journal of Environmental Monitoring and Analysis, 3(1), pp. 1-6, 2015.

[4] Lee, K.R., Kim, W.G., Yook, S.J., Woo, S.H., Kim, J.B., Bae, G.N., Park, H.K. \& Yoon, H.H., Prediction of trajectories of particles generated underneath a subway train running in an underground tunnel, Particle and Aerosol Research, 11(1), pp. 21-28, 2015. 